

\section{DISCLAIMER}

This report was prepared as an account of work sponsored by an agency of the United States Government. Neither the United States Government nor any agency Thereof, nor any of their employees, makes any warranty, express or implied, or assumes any legal liability or responsibility for the accuracy, completeness, or usefulness of any information, apparatus, product, or process disclosed, or represents that its use would not infringe privately owned rights. Reference herein to any specific commercial product, process, or service by trade name, trademark, manufacturer, or otherwise does not necessarily constitute or imply its endorsement, recommendation, or favoring by the United States Government or any agency thereof. The views and opinions of authors expressed herein do not necessarily state or reflect those of the United States Government or any agency thereof. 


\section{DISCLAIMER}

Portions of this document may be illegible in electronic image products. Images are produced from the best available original document. 
Printed in the United States of America. Available from National Technical Informalion Service

U.S. Department of Commerce

5285 Port Royal Road, Springfield, Virginia 22161

NTIS price codes-Printed Copy: A03; Microfiche A01

This report was prepared as an account of work sponsored by an agency of the United States Government. Neither the United States Government nor any agency thereof, nor any of their employees, makes any warranty, express or implied, or assumes any legal liability or responsibility for the accuracy, completeness, or usefulness of any information, apparatus, product, or process disclosed, or represents that its use would not infringe privately owned rights. Reference herein to any specific commercial product, process, or service by trade name, trademark, manufacturer, or otherwise, does not necessarily constitute or imply its endorsement, recommendation, or favoring by the United States Government or any agency therent I he views and opinions of authors expressed hereln do rout necessarily state or reflect those of the United States Government or any agency thereof. 


\section{PAGES $\mathrm{i}$ to $\mathrm{ii}$ WERE INTENTIONALLY LEFT BLANK}


CONTENTS

Page

Foreword.................... $v$

Abstract. ........................ 1

I. Introduction. ................. 1

II. Experimental Details ............... 4

III. Data Reduction añd Uiscussion............. 7

IV. Conclusions and Evaluation ............ 18

Acknowledgments .................... 22

References.................. 22 
THIS PAGE

WAS INTENTIONALLY

LEFT BLANK 
FOREWORD

In July 1980, as part of a program to measure fission products, J. W. McConnell and I irradiated a small sample of curium nitrate enriched to $>99 \%$ in the isotope ${ }^{243} \mathrm{Cm}$ with thermal neutrons and then followed the decay of the fission products created by the irradiation. Identification of particular fission-product decay was accomplished by gamma-ray assay of unseparated fission products. Measurements of gamma-ray spectra were obtained using standard Ge(Li) spectroscopy for a period of 24 months following the irradiation. The reduction of a portion of these data and the analysis of the results was the task perrurlled by Mr. Breederland, the author of this document.

Mr. Breederland is at the present time a senior attending Hope College in Holland, Michigan, majoring in computer science. This work was performed during the "Oak Ridge Science Semester," sponsored by the Great Lakes College Association/Associated Colleges of the Midwest. It was performed under my supervision.

J. K. Dickens

Engineering Physics Division

December 1981 
Contract No. W-7405-eng-26

Engineering Physics Division

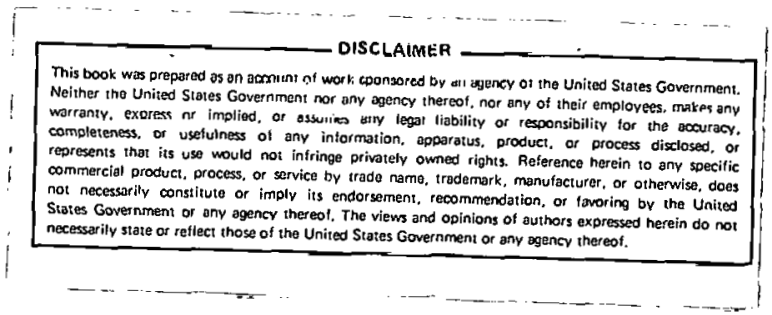

\title{
FISSION-PRODUCT YIELDS FOR THERMAL-NEUTRON FISSION OF CURIUM-243
}

\author{
David G. Breederland*
}

\begin{abstract}
NOTICE This document contains information of a preliminary nature. It is subject to revision or correction and therefore does not represent a final report.
\end{abstract}

Date Published: January 1982

*Hope College, Holland, Michigan

This Work Sponsored by Department of Energy Basic Energy Sciences

UAK RIDGE NATIONAL LABORATORY

Oak Ridge, Tennessee 37830

operated by

UNION CARBIDE CORPORATION

for the

DEPARTMENT OF ENERGY 
FISSION PRODUCT YIELDS FOR THERMAL-NEUTRON FISSION

OF CURIUM-243

David G. Breederland

ABSTRACT

Cumulative fission yields for 25 gamma rays emitted during the decay of 23 fission products produced by therma 1neutron fission of $243 \mathrm{~cm}$ have been determined. Using $\mathrm{Ge}(\mathrm{Li})$ spectroscopy, 33 success ive pulse-height spectra of gamma rays emitted from a $77-\mathrm{ng}$ sample of $243 \mathrm{Cm}$ over a period of. approximately two and one-half months were analyzed. Reduction of these spectra resulted in the identification and matching of gamma-ray energies and half-lives to specific radionuclides. Using these results, 23 cumulative fissionproduct yields were calculated. Only those radionuclides having half-lives between 6 hours and 65 days were observed. Prior to this experiment, no fission-product yields had been recorded for $243 \mathrm{Cm}$.

\section{INTRODUCTION}

A few years after the neutron was discovered by Chadwick in 1932, Fermi began producing artificial radioisotopes by irradiating elements with slow-moving, radium-beryllium-sourced neutrons. Fermi irradiated a sample of uranium in one of his experiments and discovered he had created a new isotope thought to be element 93, because he succeeded in separating elements 82 to 92 inclusive from it. The formation of element 93 would be expected from the capture of a neutron by uranium followed by beta decay. ' Fermi's "element 93" was later chemically identified to be barium.

In 1939 Hahn and Strassmann, German radiochemists, succeeded in proving that uranium, when bombarded with thermal neutrons, undergoes a nuclear change resulting in the formation of elements with about half 
the atomic number of uranium. ${ }^{2}$ This new discovery was named fission and was determined to be a radioactive decay mode.

Physicists today are studying systems ranging from ${ }^{227} \mathrm{Th}$ to ${ }^{258} \mathrm{Fm} .{ }^{3}$ The major range of interest has occurred in the systems between $234 \mathrm{U}$ and the spontaneous fission of ${ }^{252} \mathrm{Cf}$. These experiments have dealt largely with the two isotopes $235 \mathrm{U}$ and $239 \mathrm{Pu}$ because $235 \mathrm{U}$ is found in nature, can be readily attainable, and is the major energy source in today's nuclear reactors. Pu-239 is a by-product of these reactors. Hence these isotopes are studied in hopes of harnessing a safe and productive energy source. Unlike uranium, the other heavy elements are produced frum dedicated irradiations. Some are not easily attainable in a pure form and/or useful amount.

This is the case with $243 \mathrm{Cm}$. It is an isotope which is difficult to separate from impurities. A sample of curium nitrate enriched to $>99 \%$ in the isotope ${ }^{243} \mathrm{Cm}$ was obtained in the High Flux Isotope Reactor at Oak Ridge National Laboratory. Because no one had ever measured fission-product yields resulting from thermal-neutron fission of $243 \mathrm{~cm}$, the sample was irradiated with neutrons. It was my task to analyze the data taken to determine fission-product yields and a mass distribution for $243 \mathrm{Cm}$.

During low-energy fission, a heavy nuclide almost consistently breaks into two unequal masses. This is called binary fission. A very small fraction of fission, called ternary fission, will result in 3 or more fragments. Experimental results reveal that the corresponding probability of ternary fission (with the formation of alpha particles) is roughly $10^{3}$ times below that of binary fission. The frequency of ternary fission is estimated to be 1 to 3 per 1000 fission events. 4 When fission yieids of an isotope are plotted in accordance with mass, two curves representing the light and heavy mass groups separated by a trough may be observed. This is described as an asymmetric mass distribution. If one were to sum the yields under the two curves, the sum would equal $200 \%$ to represent binary fission. 5 
The major variations observed in the mass distributions as a function of increasing mass of the fissioning system are a shift in the peak of the light mass distribution and an overall broadening of the distribution of fission products created in both the light and heavy mass groups. ${ }^{3}$ For the systems between ${ }^{235} \mathrm{U}$ and ${ }^{252} \mathrm{Cf}$ the mass distributions have been predominately asymmetric. ${ }^{6}$ At this time there are no accurate theories as to why this occurs. There are, however, models currently in use which predict unmeasured yields but do not have sufficient theoretical concepts to be considered accurate. ${ }^{7}$ Hence, it is necessary to perform experiments which will supply data for comparison with predictions to help redefine concepts which may lead to a model that can determine unmeasured or unmeasurable yields.

There are specific nuclear properties ${ }^{8}$ associated with ${ }^{243} \mathrm{Cm} . \quad \mathrm{Cm}-243$ (element 96) can be produced by irradiating a sample of $241 \mathrm{Am}$ with slowmoving thermal neutrons:

$$
{ }^{241} \mathrm{Am}(\mathrm{n}, \gamma)^{242} \mathrm{Am} \quad \frac{\beta-}{16 \mathrm{hr}}{ }^{21.2} \mathrm{Cm}(\mathrm{n}, \gamma)^{243} \mathrm{Cm} \text {. }
$$

The ${ }^{241} \mathrm{Am}$ can be produced from ${ }^{2.38} \mathrm{U}$ or ${ }^{239} \mathrm{Pu}$ by the following:

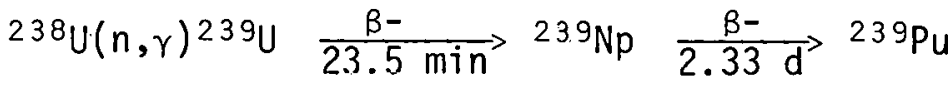

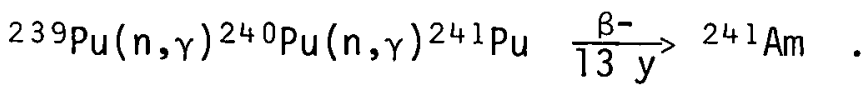

$\mathrm{Cm}-243$ decays by emission of alpha particles with a half-life determined to be 32 years. During the decay, gamma rays of 103.75, 209.76, 228.20 , and $277.87 \mathrm{keV}$ are given off.

The main objective of this project was to determine cumulative fission-product yields. This expresses the probability that a given Isotope will form both directly from fission and through decay of all of the parent isotopes. Also discussed in this paper is an independent yield, which is the probability that a given isotope will form directly in the fission process. 


\section{EXPERIMENTAL DETAILS}

Experimental details which occurred before I arrived at Oak Ridge National Laboratory and the procedures used to acquire the data during the fissioning of ${ }^{243} \mathrm{Cm}$ will be discussed in this section.

A 77-ng sample of curium nitrate, for which the ${ }^{243} \mathrm{Cm}$ enrichment was $>99 \%$, was irradiated at the High Flux Isotope Reactor pneumatic tube facility (thermal flux $\sim 5 \times 10^{14} \mathrm{n} / \mathrm{s}$ ) for $151 \mathrm{~s}$, and produced $9 \times 10^{9}$ $( \pm 7.5 \%)$ fissions. Pulse-height spectra were taken using a $\mathrm{Ge}(\mathrm{Li})$ detector fnr a period of approximately four months after the irradiation. For my project I was given 33 spectra, the first commencing $81,030 \mathrm{~s}(22.51 \mathrm{hrs})$ after the end of the irradiation and the last commencing 79.19 days after the end of the irradiation. Counting time intervals ranged between $10,281 \mathrm{~s}$ and $5.84 \times 10^{5} \mathrm{~s}$. For most of the measurements, the sample was placed $150 \mathrm{~mm}$ above the face of the detector; for the spectrum commencing at $81,030 \mathrm{~s}$, the source-to-detector distance was $200 \mathrm{~mm}$. A11 spectra but the last, taken at 79.19 days after irradiation, were analyzed over 4096 channels; the last was analyzed over 2048 channels.

The gamma-ray measurememls were set up so that as the cooling time of the ${ }^{243} \mathrm{C} . \mathrm{m}$ increased, so did the time interval over which subsequent spectra were taken. This was done to account for decay properties which are derived from the formula

$$
N=N_{0}(\exp (-\lambda t))
$$

where $N$ is the number of atoms remaining at time $t, N_{0}$ is the initial number, and $\lambda$ is the decay constant. This equation indicates that the number of atoms, out of an original total $N_{0}$ which liave not decaycd, decreased exponentially with time.

Integration of Eq. (1) yields

$$
\Delta N=\left[\left(N_{0} / \lambda\right)\left(1-\exp \left(-\lambda t_{c}\right)\right) \exp (-\lambda t)\right]
$$

where $\Delta N$ is the change of yield (in atoms) measured between $t_{c}$, with $t_{c}$ equal to the elapsed time of a data-taking interval; $1-\exp \left(-\lambda t_{c}\right)$ 
measures the amount of atoms decaying during $t_{c}$; and $\exp (-\lambda t)$ measures the amount of atoms decaying at any given time t. $\lambda$ is obtained by

$$
\lambda=\ln (2) / T_{1 / 2}
$$

where $T_{1 / 2}$ is the half-life of a given isotope. In determining isotopedecay yields, it would be optimum to keep the value of

$$
\left(1-\exp \left(-\lambda t_{c}\right)\right) \exp (-\lambda t)
$$

proportionally similar for all half-lives, as it is a measure of the Lulal decidy rate exhlbited by an isotope during both a counting interval and an instantaneous time. For example, if yields for a short-lived isotope taken at one time are to be analyzed with yields for a longerlived isotope taken at another time, the appropriate $\lambda$ 's, using Eq. (3), can be inserted into Eq. (4). Setting the equation for the short-lived isotope equal to the equation of the longer lived isotope, one can determine what time span is needed, $t_{c}$, for one of the isotopes to give a yield proportional to the second, if the second's time, $t_{c}$, is a set value. By increasing or decreasing $t_{c}$, we can readjust data-taking intervals for a short or long half-life. For short half-lives, $\lambda$ is large; for long half-lives, $\lambda$ is small. Consequently, the longer lived an isotope is, the longer the counting interval $t_{c}$ should be with respect to counting times of shorter half-lives to compensate for the decrease in magnitude of $\lambda$.

Measurements were limited in this experiment to the longer-lived fission products. When analyzing these 33 spectra, cumulative fission yields were obtained only for radionuclides having half-lives between 6 hours (135I) and 65 days $\left({ }^{5} \mathrm{Zr}\right)$. Yields could not be obtained for all nuclides within this defined set, particularly those that decay almost cntirely by beta-ray emission.

To determine fission-product yields (C), both the efficiency $\varepsilon\left(E_{\gamma}\right)$ and the fraction of the decay of the fission product giving the desired gamma ray (B), i.e., branching ratio, are required. ${ }^{9}$ Most of 
the half-life and branching ratio data were obtained from a previous report on fission-product yields. ${ }^{3}$ In the case of ${ }^{131} \mathrm{I}$ at $636.4 \mathrm{keV}$, a half-life and branching ratio was obtained from Ref. 10. The yield $(Y)$ in a particular measurement of a given gamma ray due to decay of a fission product and of its parent is given by

$$
\begin{aligned}
{[(Y / \varepsilon) / B]_{d}=} & n_{f} c_{p}^{c}\left(\frac{\lambda_{p}}{\lambda_{p}{ }^{-\lambda} d} \exp \left(-\lambda_{d} T\right)\left[1-\exp \left(-\lambda_{d} t_{c}\right)\right]\right. \\
& \left.-\frac{\lambda_{d}}{\lambda_{p}{ }^{-\lambda} d} \exp \left(-\lambda_{p} T\right)\left[1-\exp \left(-\lambda_{p} t_{c}\right)\right]\right) \\
& +n_{f} c_{d}^{i} \exp \left(-\lambda_{d} T\right)\left[1-\exp \left(-\lambda_{d} t_{c}\right)\right]
\end{aligned}
$$

where $\lambda$ is the decay constant for a specific nuclide; $T$ and $t_{c}$ are the cooling and counting times, respectively; the subscript $d$ is for the daughter fission product being analyzed; and the subscript $p$ is for the parent. In this case, $c^{i}$ is the independent yield, and $c^{c}$ is the cumulative fissinn yield. ${ }^{11}$ When the half-life of the parent is sufficiently different from that of the daughter, the formula used for the analys is may be altered. For $\lambda_{p} \ll \lambda_{d}$

$$
[(Y / \varepsilon) / B]_{d}=n_{f} C_{p}^{c} \frac{\lambda_{d}}{\lambda_{p}-\lambda_{d}} \exp \left(-\lambda_{p} T\right)\left[1-\exp \left(-\lambda_{p} t_{c}\right)\right]
$$

and it is the cumulative fission-yield of the parent which is obtained. For $\lambda_{p} \gg \lambda_{d}$

$$
[(Y / \varepsilon) / B]_{d}=n_{f}\left(C_{d}^{i}+C_{p}^{c} \frac{\lambda_{p}}{\lambda_{p}-\lambda_{d}}\right) \exp \left(-\lambda_{d} T\right)\left[1-\exp \left(-\lambda_{d} t_{C}\right)\right]
$$

and the cumulative fission-yield of the daughter is ubldined rrom

$$
c_{d}^{c}=c_{d}^{i}+c_{p}^{c}
$$




\section{DATA REDUCTION AND DISCUSSION}

This section uses the information from Section Il to reduce the pulse-height spectra into meaningful data.

As pulse-height spectra were taken, the gamma rays emitted were stored as channels, not energies. Hence, an energy-calibration factor had to be calculated to transform the 4096 channels into spectra depicting energies. Known gamma rays were found on a pulse-height spectrum. By correlating a channel number with a known energy, the rest of the spectrum could be deciphered. There were three such calibrations made. It was determined that channel 160 was at $140.5 \mathrm{keV}$ ('yyMo), channel 1747

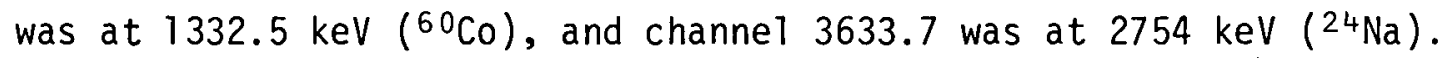
Figure 1 shows a low energy spectrum taken 10.3 days after the irradiation. Figure 2 shows a higher energy spectrum taken at the same time. In both figures, labeled peaks correspond to nuclides investigated.

The pulse-height data were then reduced using a computer software package entitled TPASS which uses Eq. (5) as a basis for its calculations. ${ }^{12}$ Using this routine, gamma-ray peaks in the 4096-channel spectrum are identified, areas under the peak are determined, and the energy of the responsible gamma ray is obtained from the energy calibrations. Peak yields are corrected for detection efficiencies, and where possible the radionuclide source is identified by comparison with an isotope gamma-ray decay table.

In associating peaks with gamma-ray energies, the code allows for a variance in $E_{\gamma}$, as determined by the user. For this project, a 1.3-keV variance was used. This takes into consideration variations which may occur in the detection system. Single peaks, and on the whole most doublets, were properly assigned individual isotopic peak areas.

Resolution widths under ideal counting conditions as a function of $\mathrm{E}_{\gamma}$ for the $\mathrm{Ge}(\mathrm{Li})$ detector used in this experiment are known by the code. These are taken into account accordingly if identification of energies can be assigned. These energies, $E_{\gamma}$, are then used to obtain the efficiency $\varepsilon\left(E_{\gamma}\right)$. 
ORNL-DWG $81-21718$

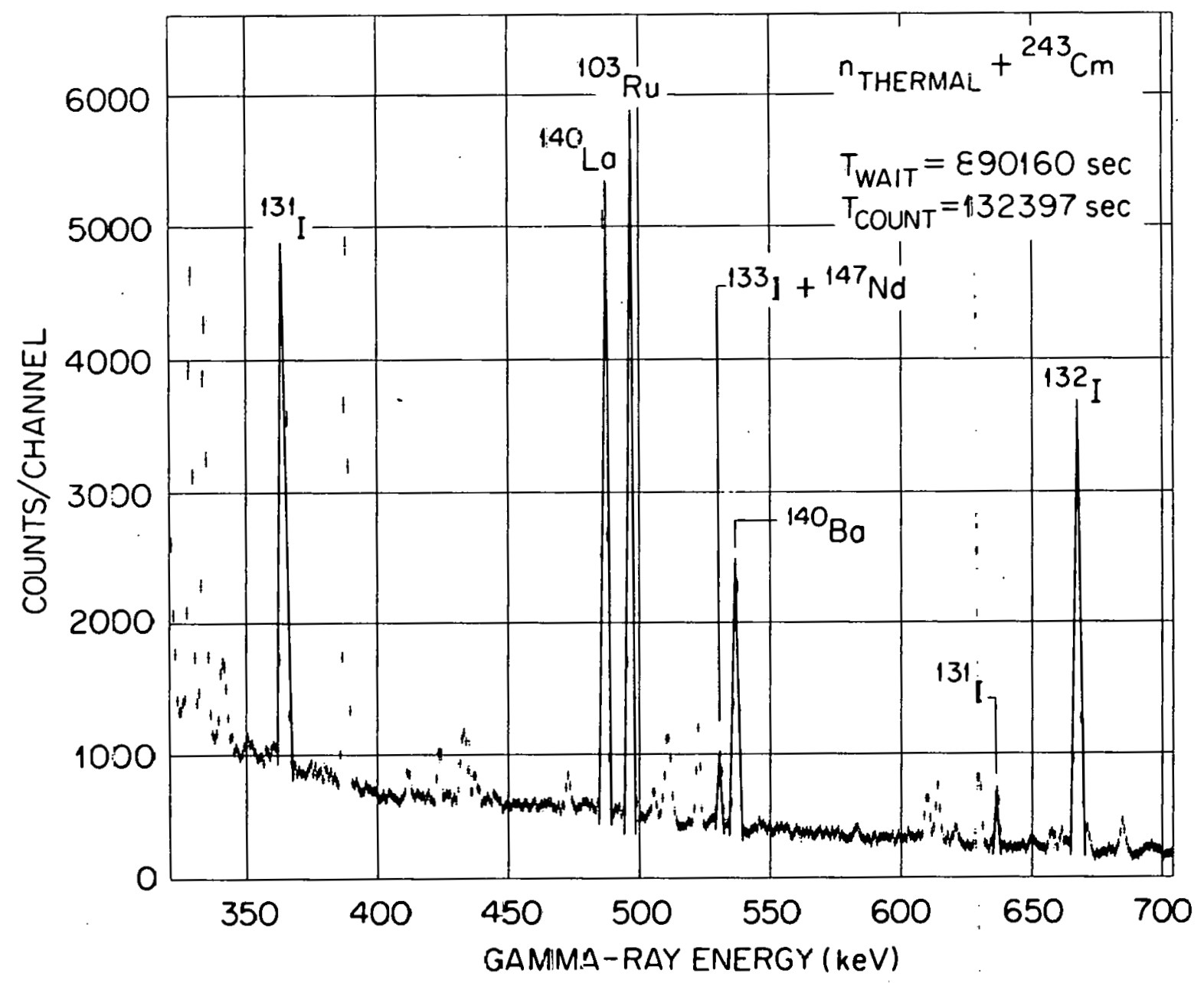

Fig. 1. Pulse-height spectrum of ganma rays following a $151-$ s irradiation of a $243 \mathrm{Cm}$ sample by thermal neutrons. Symbols indicate gama-ray energy (in kev) and responsible isotope for fission products studied. Major peaks which maji also be seen but not studied include $140 \mathrm{La}$ at $328.65 \mathrm{keV}$ and $131 \mathrm{Te}+243 \mathrm{Cm}$ at $333.43 \mathrm{keV}$. 


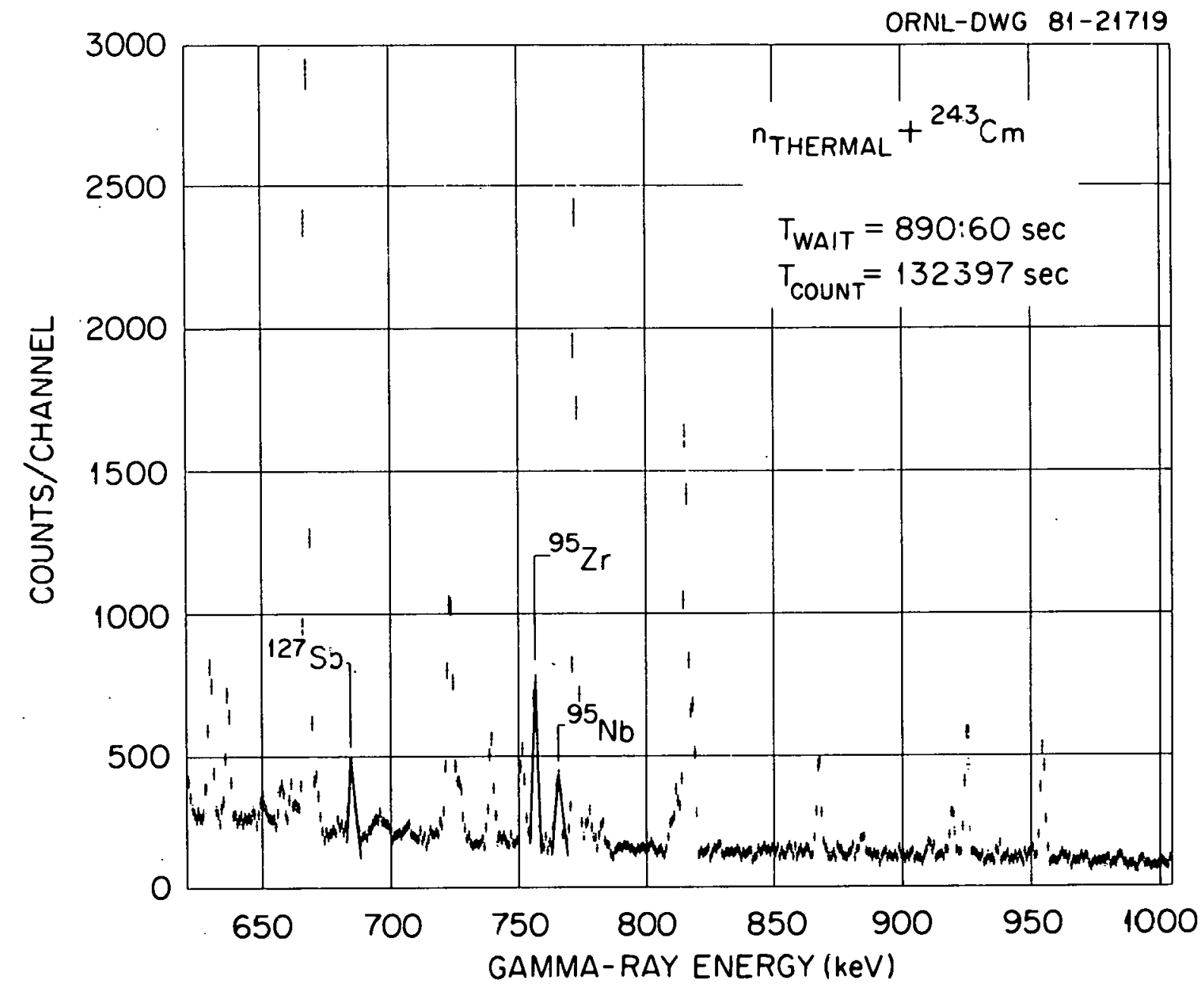

Fig. 2. Higher-energy portion of the spectrum shown in Fig. 3. Maior peaks which may also be seen but not studied include 132 I at $667.48 \mathrm{keV}, 131 \mathrm{Te}+132 \mathrm{I}$ at $772.44 \mathrm{keV}$, and $140 \mathrm{La}$ at $815.52 \mathrm{keV}$. 
After analyses are performed on a given spectrum, a comparison is made between $E_{\gamma}$, as determined from the raw data, and the isotope table values. If $E_{\gamma}$ in the gamma-ray decay table cannot be found in the raw data, the code will search the spectrum again in the appropriate region of energy where the gamma ray should be located. If a peak is found to result from more than one nuclide, it is identified as such. This situation occurred for two doublet peaks; one of them at $228.2 \mathrm{keV}$ with ${ }^{132} \mathrm{Te}$ and the source ${ }^{243} \mathrm{Cm}$, and the other at $531 \mathrm{keV}$, with ${ }^{133} \mathrm{I}$ and ${ }^{147} \mathrm{Nd}$. Figure 1 shows this latter peak in the pulse-height spectrum. Both cases required a modified least squares algorithm to distinguish between the two nucilides. Figure 3 shows the distinction made between the ${ }^{133} \mathrm{I}$ and ${ }^{147} \mathrm{Nd}$. There are two distinct half-life curve separations, with a half-life of 20.8 hours assigned to the ${ }^{133} \mathrm{I}$, and a half-life of 11.06 days assigned to the ${ }^{147} \mathrm{Nd}$.

After the 33 spectra were reduced, for each radionuclide of interest the yield (in the form of number of atoms) along with its deviation during one of the 33 intervals was plotted. This was done for the intervals in which the isotope is detected. Ideally, these yields should be fairly consistent. Figure 4, showing ${ }^{131} \mathrm{I}$ at $636.9 \mathrm{keV}$, represented by solid points, is an example of this step in data reduction. Since the yields varied, however, it was necessary to ascertain if the code actually performed the reduction correctly, if there were difficultles analyzing a particular peak, or if there were faults in the data. In Fig. 4, data taken at $1.85,2.0,2.48,2.86,3.14,4.1,5.9,19.85,22.91,26.21,30.4$, and 40.06 days for the nuclide ${ }^{131} \mathrm{I}$ at $636.9 \mathrm{keV}$ deviated from the average more than expected. Surrounding points to these were also analyzed to compare "satisfactory" measurements with those considered to be incorrect. In some instances, namely at $4.85,5.31$, and 14.95 days, the "satisfactory" measurements were also improved.

Consequently, the next step in the data reduction was to take these points in question and plot the actual raw data from the original spectrum. A "background" line was drawn from one base of the peak to the other. This gave a bounded area under the curve to analyze. A smaller, more specific area under the peak consisting of five channels which centered 


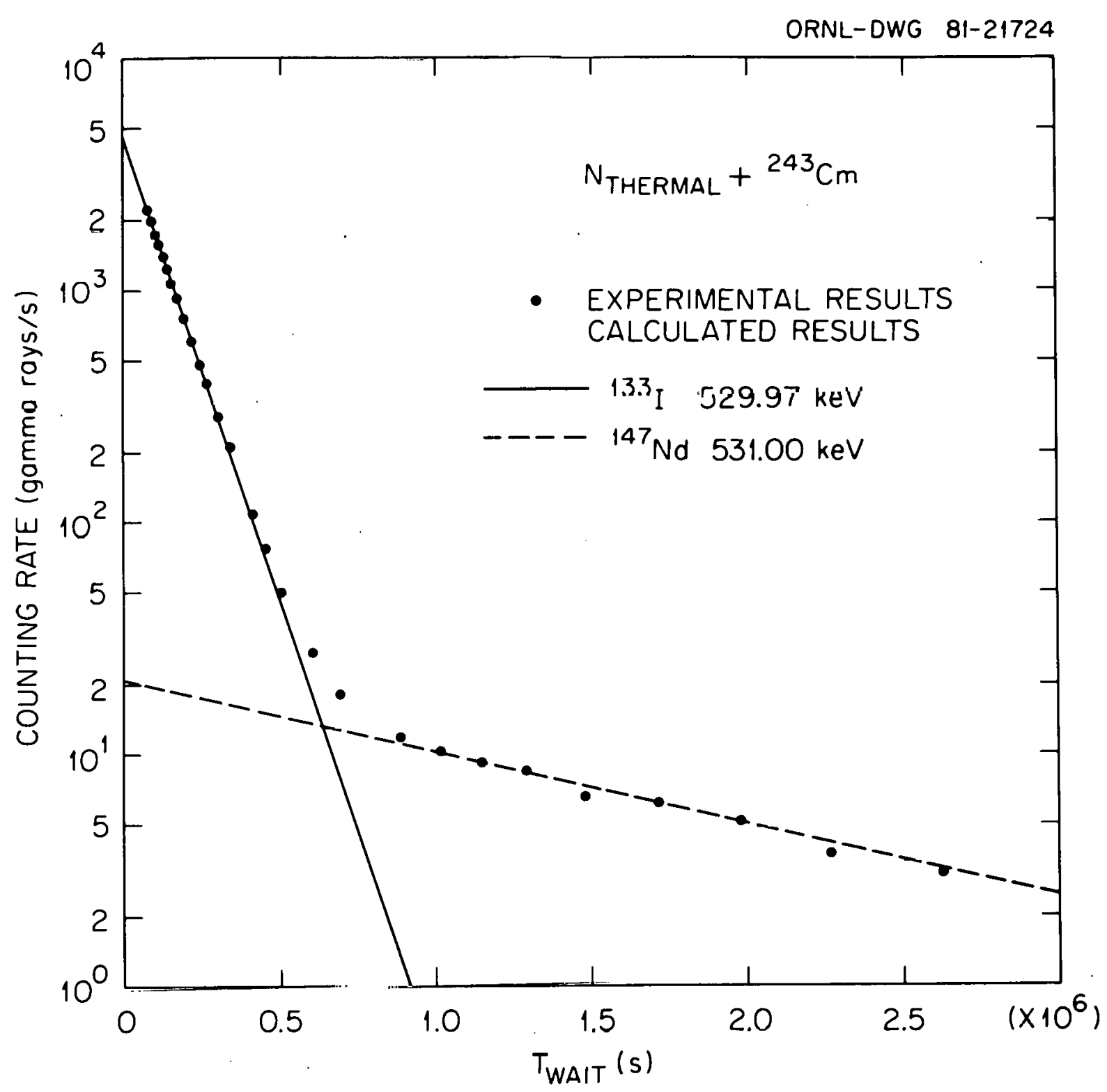

Fig. 3. Decay of ${ }^{133} \mathrm{I}$ and ${ }^{147} \mathrm{Nd}$ formed during thermal-neutron fission of $243 \mathrm{~cm}$. The two isotopes were within $1 \mathrm{keV}$ of each other, thus showing up on the same energy peak. A 20.8-h half-life has been assigned to ${ }^{13} \mathrm{I}$, while ${ }^{147} \mathrm{Nd}$ has a half-life of 11.06 days. 


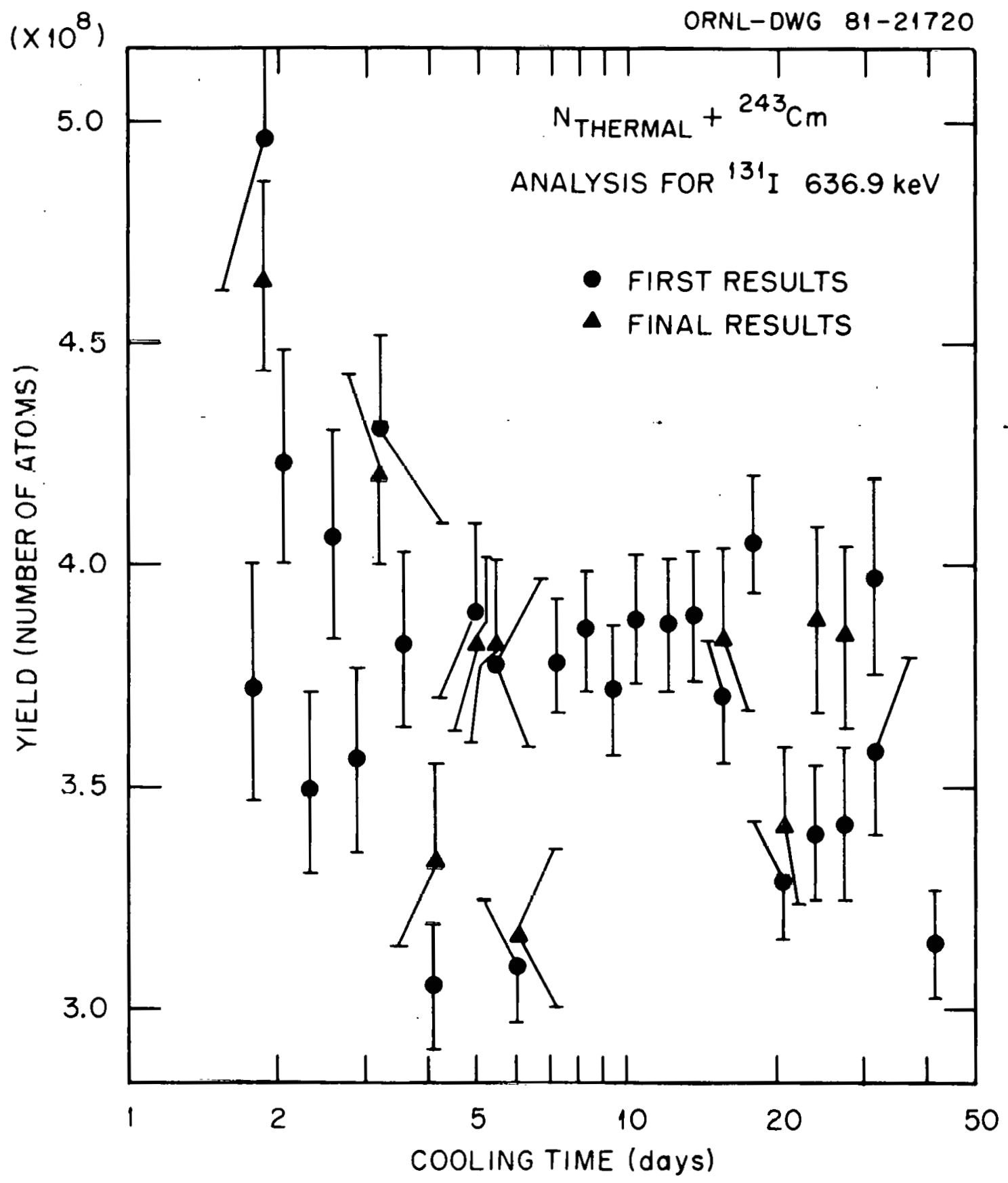

Fig. 4. Analysis of data obtained for $E_{y}=636.9 \mathrm{keV}$ assigned to decay of $13 \mathrm{i}$. Darkened circles represent measurements of the yield (in number of atoms) as they were first calculated and obtained during 25 subsequent pulse-height spectrum measuremiencs. If a darkened triangle appears at the same cooling time a circle appears, this signifies that the original calculation was determined to be incorrect and was recalculated to a value represented by the triangle. 
around the top point was then reduced. The five background points, each represented by $B P$, were summed for each run. An associated counting time was then divided into each $\Sigma B P$ and $\sqrt{\Sigma B \bar{P}}$, to obtain a point and its associated uncertainty, respectively. These were then graphed on the same $x$-axis as was done with the yields. Figure 5 illustrates the calculated background points of ${ }^{131} \mathrm{I}$ at $636.9 \mathrm{keV}$. When a curve was fit to these points, it was frequently similar to the exponential curve. Points at $2,2.48,2.86,3.14$, and 4.1 days were repositioned so they would be consistent with the rest of the estimations.

The next step was to obtain a new yield for $E_{\gamma}$. This was accomplished by subtracting the sum of the five background points from the sum of corresponding peak points. By dividing this result with the yield calculated by the code, and further multiplying by the number of atoms that were present, a revised point on the "atoms" graph was obtained. If this approximation was closer to the average of points, the initial yield was recalculated. In Fig. 4 , those points represented by a $\Delta$ were found to be better approximations.

After doing this for each nuclide and finding no real surprises, the data, either originally obtained or changed, were ready to be reduced for the final cumulative-yield calculations.

Files for the purpose of using Eq. (5), Eq. (6), or Eq. (7) to obtain fission-product yields were created for each spectrum, listing count times, wait times, energies associated with $E_{y}{ }^{\prime} s$, their associated/corrected yields, and the uncertainties associated with those yields. Figure 6 is an excellent example showing the properties stated by Eq. (5). In this diagram, the parent nuclide, ${ }^{9} \mathrm{Zr}$, can be seen decaying into the daughter nuclide ${ }^{95} \mathrm{Nb}$. Figure 7 shows the half-life curves for $97 \mathrm{Zr}$ at

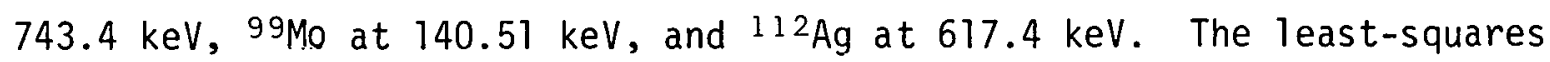
fitting procedures applied to any one of the data sets shown in Figs. 3 , 6 , and 7 gave a best-fit decay constant $\lambda$ and $Y_{0}$, as well as uncertainties associated with these calculations. When the decay constant $\lambda$ is inserted into Eq. (3), a calculated half-life for an isotope may be obtained. On the whole, most of the experimental half-life figures, when compared to given half-lives, were within the associated uncertainties. 


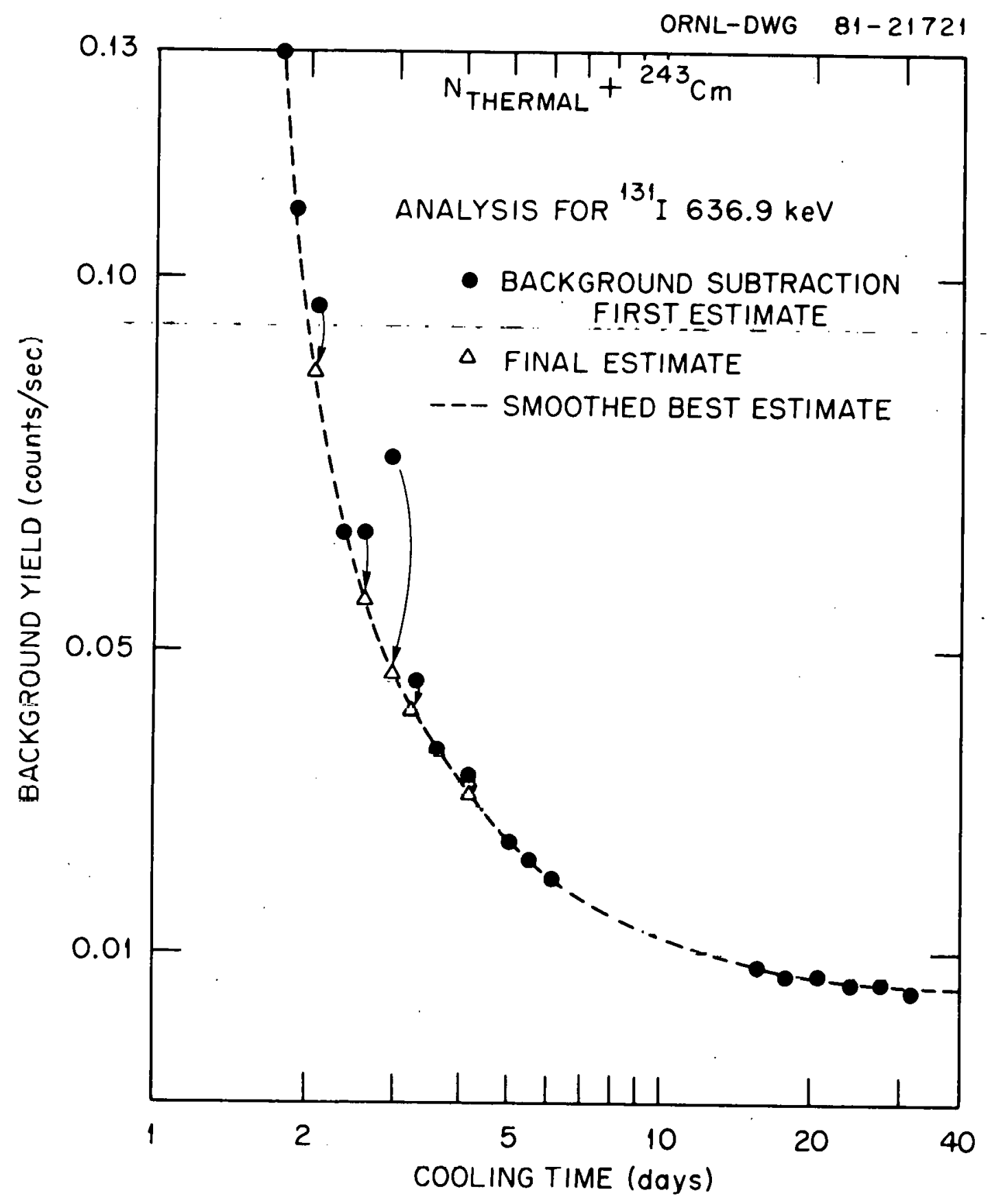

Fig. 5. Analysis of data obtained for $E_{\gamma}$ at $636.9 \mathrm{keV}$ assigned to the decay of $131 \mathrm{I}$. Plot shows background subiraction estimations for Fig. 5 for those points deviating from the average. 


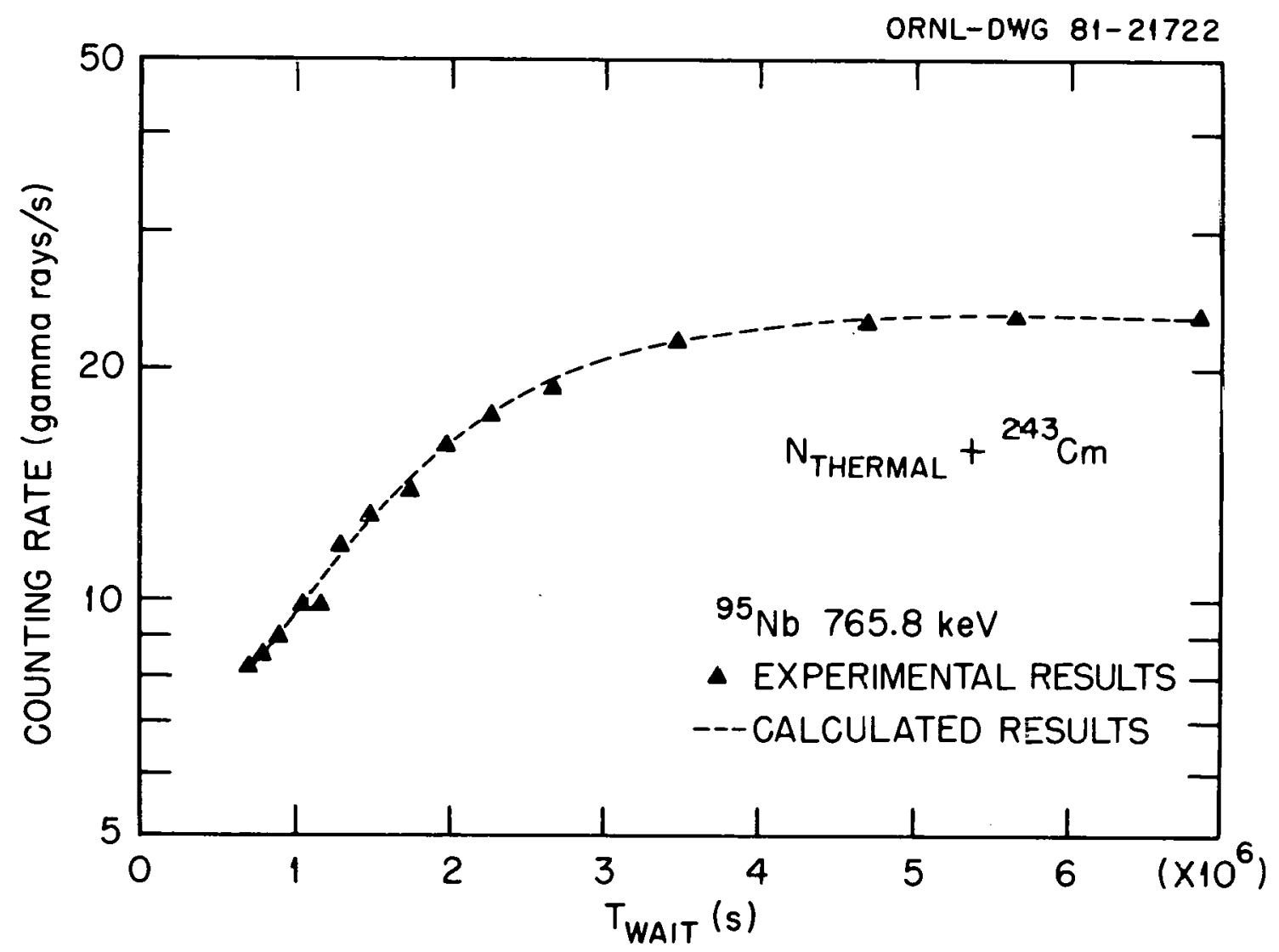

Fig. 6. Decay of the parent nuclide, ${ }^{95} \mathrm{Zr}$, into its daughter, ${ }^{95} \mathrm{Nb}$, as a result from thermalneutron fission of $243 \mathrm{~cm}$. 


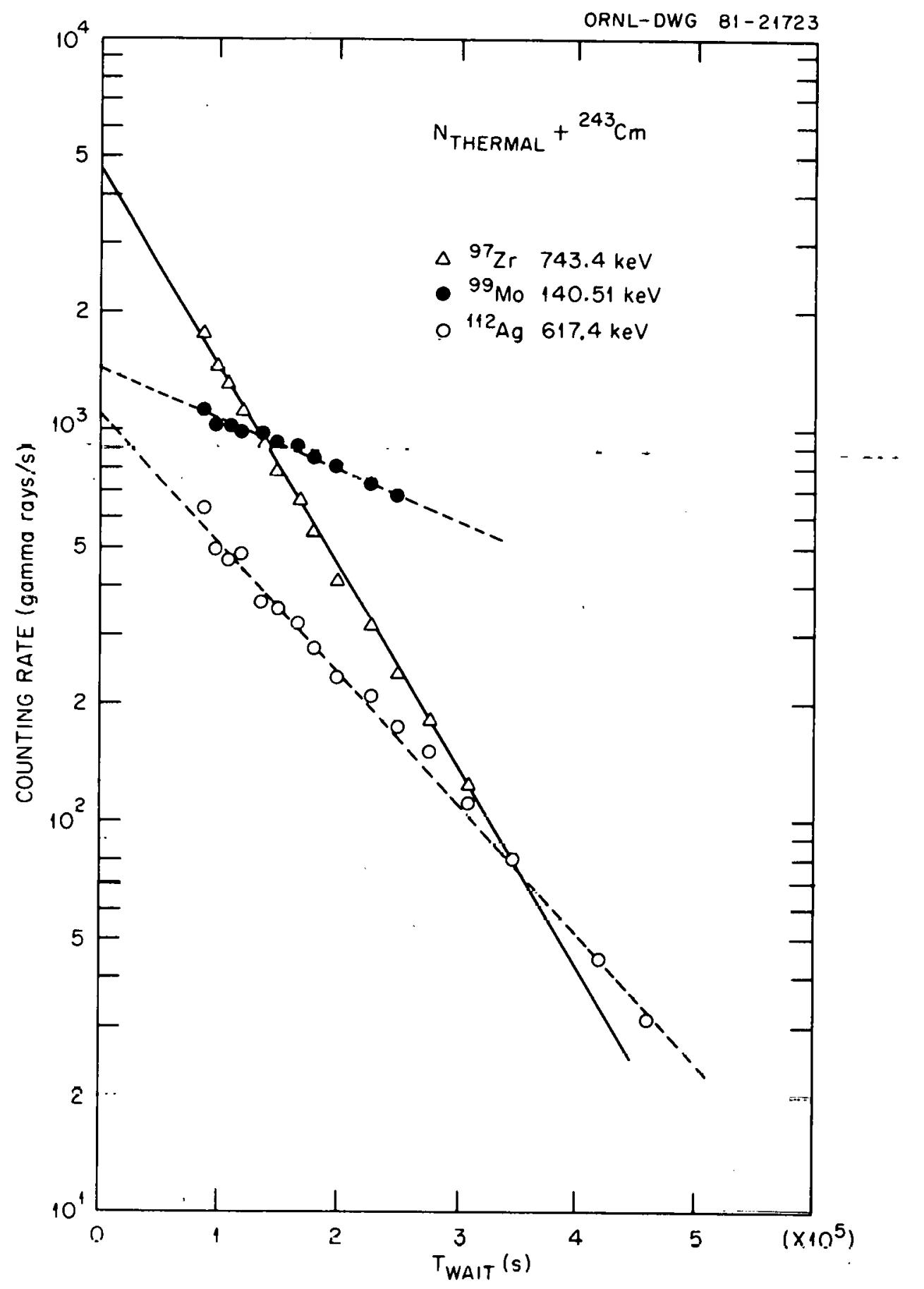

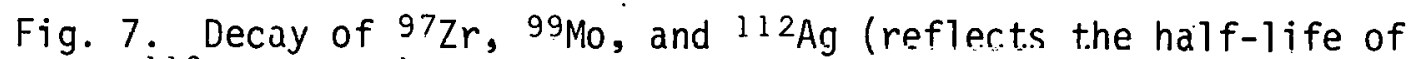
its 21.0-h $112 \mathrm{Pd}$ parent), formed during thermal-neutron fission of $243 \mathrm{Cm}$. 
A search for several preselected isotopes was made through each file in an attempt to find the energies corresponding to the isotopes being sought. If an $E_{\gamma}$ was found, the next step in the data reduction was to determine the amount of atoms present directly after the thermal-neutron irradiation took place. The process which was used to do this may be simplified, for easier understanding, by being broken down into two components. It should be noted this explanation is simplified and represents the one component process which actually took place.

The first step, if an $E_{\gamma}$ was found, used the calculation

$$
S=\bar{Y} /[1 \operatorname{cxp}(-\lambda T)]
$$

where $\bar{Y}=Y / \varepsilon[=y i e 1 d$ (in the form of number of atoms) $]$ at time $T$ and $\lambda$ is related to the half-life by Eq. (3), to derive points which when plotted against the wait time, depicts the half-life of a nuclide. The second step performed a least-squares fit to each nuclides' points and determined a $\mathrm{Y}$-intercept or the amount of atoms present directly after the thermalneutron irradiation. This information was then used in calculations of fission yields. Figures 3 and 7 show this step in the data reduction.

When observing these half-life curves, the smaller the slope the longer half-life a nuclide has. In Fig. $7,{ }^{97} \mathrm{Zr}$ has a half-life of 16.9 hours, ${ }^{9}$ Mo has a half-7ife of 66.11 hours, and ${ }^{112} \mathrm{Ag}$ reflects the halflife of its 21.0-hour 112 pd parent.

For each isotope found, $Y_{0} / \lambda$ and the uncertainty $\Delta\left(Y_{0} / \lambda\right)$ was computed. Then the cumulative fission product yield, $C$, was determined from

$$
C=\left(Y_{0} / \lambda\right) /\left(\varepsilon B n_{f}\right),
$$

where $\varepsilon\left(E_{\gamma}\right)$ is the gamma-ray detection efficiency and $B$ is the branching ratio. The uncertainty $\Delta C$ was obtained by appropriately combining the uncertainties $\Delta\left(Y_{0} / \lambda\right), \Delta n_{f}$, and $\Delta B$. In this manner, 23 cumulative fission-product yields were determined for $243 \mathrm{~cm}$.

Also calculated for this project were yields per 100 fissions. These figures were calculated using the equation 


$$
100 \times\left[\left(\gamma_{0} / \lambda\right) / n_{f}\right]
$$

where the variables are described under Eq. (10). The final results and calculations for this experiment are recorded in Table 1.

\section{CONCLUSIONS AND EVALUATION}

The objective of this experiment was to acquire cumulative fissionproduct yields for the longer-lived isotopes during thermal-neutron fission of ${ }^{243} \mathrm{~cm}$. Twenty-three such yields were determined by gamma-ray assay. There are no other data of this type available for ${ }^{21}{ }^{3} \mathrm{~cm}$.

It has been determined that ${ }^{243} \mathrm{Cm}$ displays the asymmetric mass distribution similar to other heavy isotopes. 3,7,13-14 Figure 8 , the light mass curve, depicts the fissioning of ${ }^{245} \mathrm{~cm}$ (ref. 3 ) and the present results obtained for ${ }^{243} \mathrm{~cm}$. The curve for the ${ }^{245} \mathrm{~cm}$ has shifted two units (one unit for each increase in the atomic number) to the right of the ${ }^{243} \mathrm{~cm}$. Figure 9 , the heavy mass curve, tends to remain the same for both isotopes. Where there were more than one nuclide for a given mass (nlamely, mass numbers of $91,95,97,131,132,140$ ), the yields for each mass were summed with the average being plotted. Pruducts represented by points on the left-hand (outer) side of the light masses will correspond to those of the same yield on the right-hand (outer) side of the heavy masses. Similarly, products on the right-hand (inner) side of the light masses will be paired with those on the left-hand (inner) side of the heavy masses.

The data reduction gave yields for selected gamma rays. The calculated values are shown in Table 1. Also tabulated were yields per 100 fissions, gamma-ray branching ratios, and half-lives for the daughter and parent. Because fission yields had never been measured for ${ }^{243} \mathrm{~cm}$, there was no way to make comparisons with other studies. Overall, there were very few data which gave difficulties; the exceptions were the two doublet peaks, ${ }^{132} \mathrm{Te}$ with the source ${ }^{24} \mathrm{Cm}$, and ${ }^{133} \mathrm{I}$ with ${ }^{1 !}{ }^{7} \mathrm{Nd}$. The cumulative fission-product yield for ${ }^{136} \mathrm{Cs}$ at $1048.1 \mathrm{keV}$ was low, since it is a shielded nuclide. A shielded nuclide is one which cannot be 


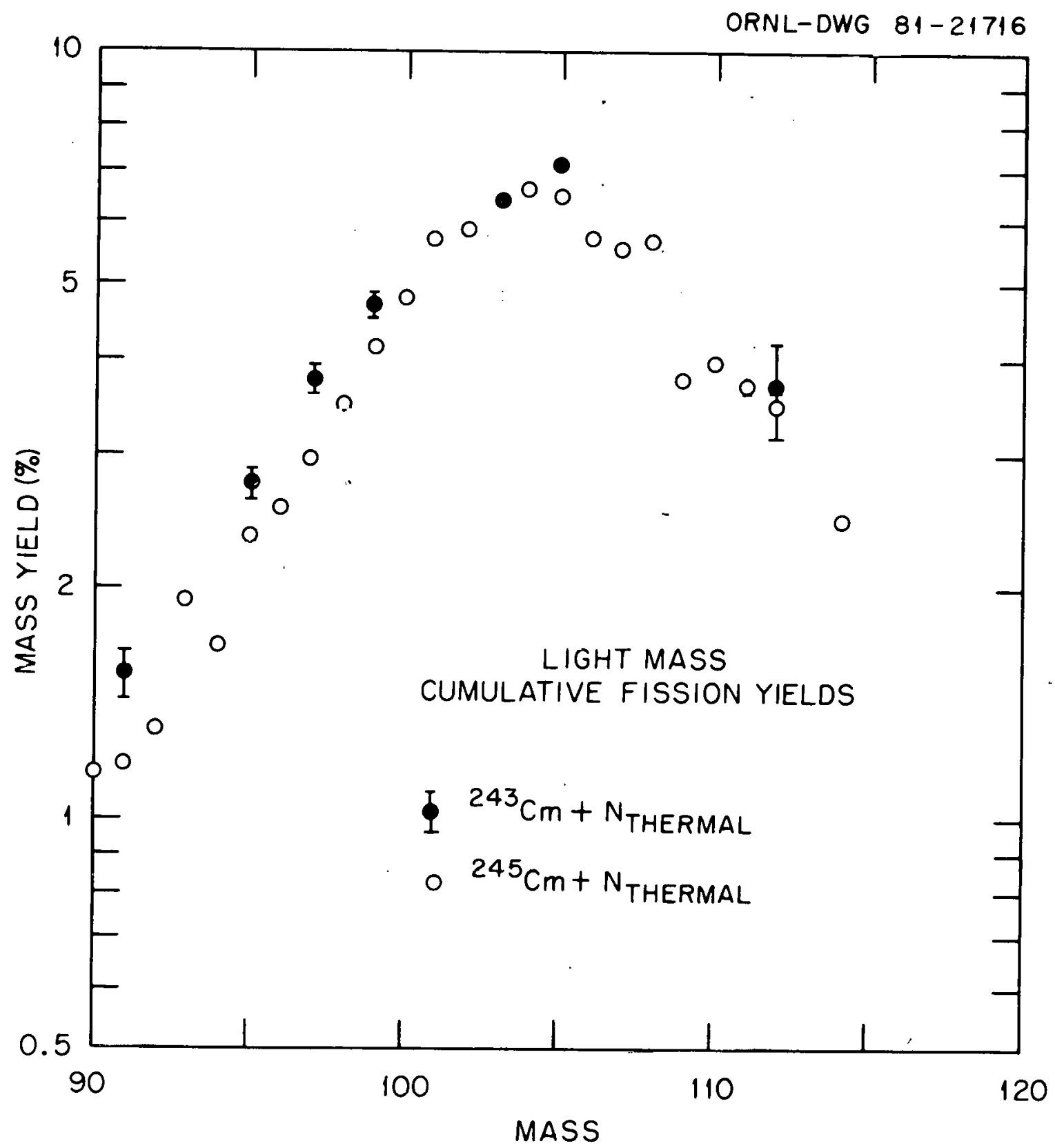

Fig. 8. Light mass-yield distribution for $n_{\text {thermal }}+243 \mathrm{Cm}$ derived from the present measurements. Also shown for comparison are measurements representing the $n$ thermal $+245 \mathrm{Cm}$ mass distribution. The ${ }^{245} \mathrm{Cm}$ curve has been shifted to the right of the ${ }^{243} \mathrm{Cm}$ curve by two units, one unit for each increase in the atomic number. 


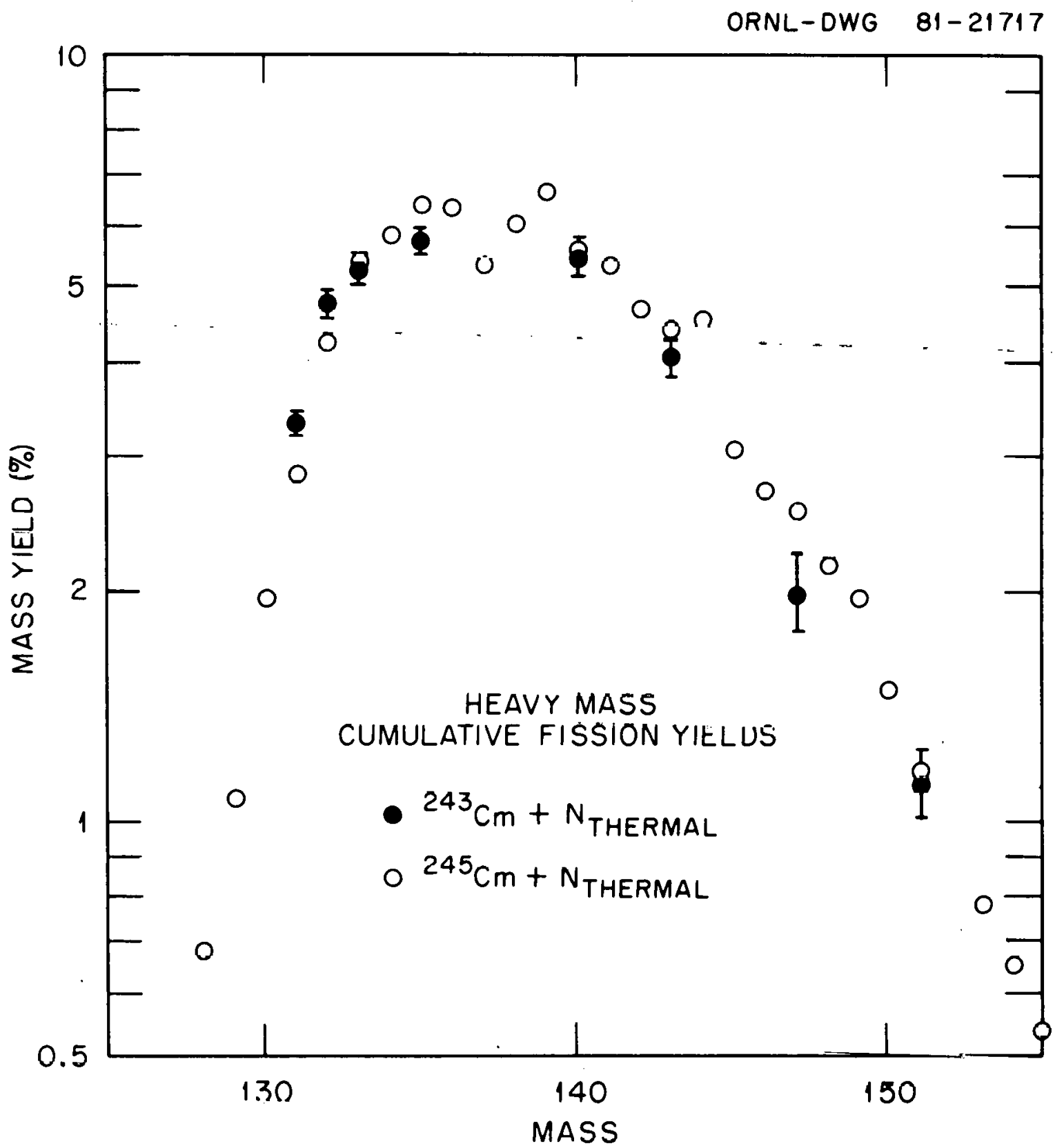

Fig. 9. Heavy mass-yield distribution for nthermal $+243 \mathrm{Cm}$ derived from the present measurements. Also shown for comparison are measurements representing the $n_{\text {thermal }}+245 \mathrm{Cm}$ mass distribution. The two curves appear to be similar. 
Table 1. Intensities of gamma rays associated with decay of fission products created by thermal-neutron fission of ${ }^{243} \mathrm{Cm}$ and deduced fission-product yields $a$

\begin{tabular}{|c|c|c|c|c|}
\hline $\begin{array}{c}E_{\gamma} \\
(k e V)\end{array}$ & $\begin{array}{l}\text { Yield per } \\
100 \text { fissions }\end{array}$ & $\begin{array}{c}\text { Assigned } \\
\text { fission product. }\end{array}$ & $\begin{array}{c}\text { Gamma-ray } \\
\text { branching ratio } \\
(\%)\end{array}$ & $\begin{array}{c}\text { Cumulative } \\
\text { fission } \\
\text { product yield } \\
(\%)\end{array}$ \\
\hline 140.51 & $4.72 \pm 0.06$ & $99 \mathrm{Mo}$ & $90.7 \pm 0.6$ & $5.21 \pm 0.07$ \\
\hline 228.33 & $4.36 \pm 0.13$ & ${ }^{132} \mathrm{Te}$ & $88.2 \pm 0.2$ & $4.95 \pm 0.15$ \\
\hline 293.28 & $1.88 \pm 0.02$ & ${ }^{143} \mathrm{Ce}$ & $43.4 \pm 2.0$ & $4.34 \pm 0.20$ \\
\hline 318.9 & $1.52 \pm 0.02$ & ${ }^{105} \mathrm{Rh}$ & $19.2 \pm 0.2$ & $6.94+0.08$ \\
\hline 340.1 & $0.280 \pm 0.003$ & ${ }^{15} \mathrm{I} \mathrm{Pm}$ & $22.3 \pm 0.5$ & $1.25 \pm 0.03$ \\
\hline 364.5 & $3.04 \pm 0.03$ & ${ }^{131} I$ & $82.5 \pm 0.4$ & $3.69 \pm 0.04$ \\
\hline 487.0 & $2.88 \pm 0.03$ & $140 \mathrm{La}$ & $43.0 \pm 1.4$ & $6.69 \pm 0.22$ \\
\hline 497.1 & \pm 0.06 & ${ }^{103} \mathrm{Ru}$ & $90.9 \pm 0.7$ & $6.78 \pm 0.07$ \\
\hline 529.97 & $5.08 \pm 0.05$ & ${ }^{133} \mathrm{I}$ & $87.3 \pm 0.2$ & $5.82 \pm 0.06$ \\
\hline 531.0 & $0.276 \pm 0.003$ & ${ }^{147} \mathrm{Nd}$ & $13.1 \pm 0.8$ & $2.11 \pm 0.13$ \\
\hline 537.60 & $1.30 \pm 0.01$ & $140 \mathrm{Ba}$ & $24.4 \pm 0.2$ & $5.33 \pm 0.05$ \\
\hline 555.6 & $0.960 \pm 0.014$ & ${ }^{91} Y$ & $95.1 \pm 0.1$ & $1.01 \pm 0.02$ \\
\hline 617.4 & $1.71 \pm 0.35$ & $112 \mathrm{Ag}$ & $42 \pm 5$ & $4.07 \pm 0.95$ \\
\hline 636.9 & $0.256 \pm 0.005$ & ${ }^{131} \mathrm{I}$ & $7.24 \pm 0.09^{b}$ & $3.53 \pm 0.09$ \\
\hline 657.9 & $4.15 \pm 0.04$ & ${ }^{97} \mathrm{Nb}$ & $98.34 \pm 0.11$ & $4.22 \pm 0.04$ \\
\hline 667.76 & $4.66 \pm 0.05$ & $132 I$ & $98.7 \pm 0.1$ & $4.72 \pm 0.05$ \\
\hline 685.7 & $0.243 \pm 0.003$ & ${ }^{127} \mathrm{Sb}$ & $36.6 \pm 0.5$ & $0.66 \pm 0.01$ \\
\hline 743.4 & $3.96+0.04$ & ${ }^{97} \mathrm{Zr}$ & $97.96 \pm 0.06$ & $4.04 \pm 0.04$ \\
\hline 756.7 & $1.55 \pm 0.02$ & ${ }^{95} \mathrm{Zr}$ & $54.6 \pm 0.5$ & $2.83 \pm 0.04$ \\
\hline 765.8 & $3.29 \pm 0.03$ & ${ }^{95} \mathrm{Nb}$ & $99.82 \pm 0.01$ & $3.30 \pm 0.03$ \\
\hline 852.2 & $0.267 \pm 0.004$ & ${ }^{131} \mathrm{Te}^{\star}$ & $21.3 \pm 0.9$ & $1.25 \pm 0.06$ \\
\hline 1024.3 & $0.586 \pm 0.027$ & ${ }^{91} \mathrm{Sr}$ & $33.5 \pm 0.7$ & $1.75 \pm 0.19$ \\
\hline 1048.1 & $0.414 \pm 0.005$ & ${ }^{136} \mathrm{Cs}$ & $79.8 \pm 0.9$ & $0.52 \pm 0.01^{c}$ \\
\hline 1260.4 & $1.87+0.12$ & ${ }^{135} \mathrm{I}$ & $29.0 \pm 0.4$ & $6.26 \pm 0.37$ \\
\hline 1596.6 & $6.01 \pm 0.07$ & $140 \mathrm{La}$ & $95.4 \pm 0.08$ & $6.30 \pm 0.07$ \\
\hline
\end{tabular}

${ }^{a}$ A11 nuclear data taken from Reference 3. ${ }^{b}$ These values taken from Reference 10. shielded. 
formed by beta decay because the isobaric nuclide of the next lower atomic number is stable. Thus, their fission yields are independent rather than cumulative. ${ }^{15}$ The results in Table 1 add to the prior knowledge about ${ }^{243} \mathrm{~cm}$, the understanding of the behavior of heavy nuclei under such conditions, and comprehension of the fission process. As a greater knowledge of the overall fissioning system is acquired, there may some day be a model which will accurately depict energies released and fission-products produced during fission without having to perform the actual measurements.

\section{ACKNUWLËUGMENTS - -}

I want to express my appreciation to J. K. Dickens for his guidance and cooperation during this project and to Sue Damewood for carefuT editing and manuscript preparation.

\section{REFERENCES}

1. E. K. Hyde, The Nuclear Propertics of the Heavy Elements, Vol. III: Fission Phenomella, Prentice-Hall, New Jersey, 1965, p. 3.

2. Ibid., p. 4.

3. J. K. Dickens and J. W. McConne11, Phys. Rev. C 23, 331 (1981).

4. Y. Zysin, A. Lbov, and L. Sel'chengov. Fission Product Yields and Their Mass Distribution, Consultants Bureau, New York, 1964, p. 8.

5. Ibid., p. 3 .

6. H. W. Schmitt, Physics and Chemistry of Fission, IAEA, Vienna, 1969, p. 67.

7. J. K. Dickens and J. W. McConne11, Phys. Rev. C 24, 192 (1981).

8. E. Hyde, I. Periman, and G. Seaborg, The Nuclear Properties of the Heavy Elements, Vol. II: Detailed Radioactivity Properties, Prentice-Ha11, New Jersey, 1964, p. 891. 
9. J. K. Dickens and J. W. McConne11, Nucl. Sci. Eng. 73, 42 (1980).

10. Table of Isotopes, edited by C. M. Lederer and V. S. Shirley, seventh edition, Wiley, New York, 1978.

11. J. K. Dickens, J. W. McConnell, and K. J. Northcutt, Nucl. Sci. Eng. 77, 148 (1981).

12. J. K. Dickens, TPASS, A Gamma-Ray Spectrum Analysis and Isotope Identification Computer Code, ORNL-5732 (1981).

13. E. A. C. Crouch, At. Data Nucl. Data Tables 19, 419 (1977).

14. H. N. Erten and N. K. Aras, J. Inorg. Nucl. Chem. 41, 149 (1979).

15. E. K. Hyde, The Nuclear Properties of the Heavy Elements, Vol. III: Fission Phenomena, Prentice-Hall, New Jersey, 1964, p. 141. 


\section{THIS PAGE \\ WAS INTENTIONALLY \\ LEFT BLANK}


ORNL/TM-8168

\section{INTERNAL DISTRIBUTION}

$\begin{aligned} \text { 1-2. } & \text { L. S. Abbott } \\ 3 . & \text { R. G. Alsmiller, Jr. } \\ \text { 4. } & \text { D. E. Bartine } \\ 5 . & \text { C. E. Bemis, Jr. } \\ \text { 6-10. } & \text { J. K. Dickens } \\ 11 . & \text { G. F. Flanagan } \\ \text { 12. } & \text { D. C. Larson } \\ 13 . & \text { F. C. Maienschein } \\ \text { 14. } & \text { B. F. Maskewitz } \\ \text { 15. } & \text { J. W. McConnel1 } \\ \text { b-2U. } & \text { R. W. Peelle } \\ \text { 21. } & \text { S. Raman } \\ 22 . & \text { C. R. Weisbin } \\ 23 . & \text { A. Zucker }\end{aligned}$

24. P. W. Dickson, Jr. (consultant)

25. H. J. C. Kouts (consultant)

26. W. B. Loewenstein (consultant)

27. Richard Wilson (consultant)

28-28. Laboratory Records

30. Laboratory Records-RC

31. ORNL Patent Office

32. Central Research Library

33. ORNL Y-12 Technical Library Document Reference Secliun

\section{EXTERNAL DISTRIBUTION}

34-60. Technical Information Center (TIC)

61. Office of Assistant Manager for Energy Research and Development, Department of Energy, Oak Ridge Operations, Oak Ridge, TN 37830

62. T. R. England, Los Alamos National Laboratory, Los Alamos, NM 87545

63. B. F. Rider, General Electric Company, Vallecitos Nuclear Center, Pleasanton, CA 94566

64. S. L. Whetstone, Division of Nuclear Sciences, Office of Basic Energy Sciences, U.S. Department of Energy, Rm G-355, Washington, DC 20545

65-70. David G. Breederland, 1485 Center Sl., Zeeland, MI 49464 